\title{
Direito Civil Comparado
}

\author{
Ernesto Leme \\ Catedrático de Direito Comercial na \\ Faculdade de Direito da Universidade \\ de São Paulo.
}

I

Sumário: Importância do estudo do Direito Comparado. O Direito Comparado como disciplina auxiliar. O Direito Comparado como simples método. O Direito Comparado como ciência autônoma. Suas divisões.

Importância do estudo do Direito Comparado. - O interêsse dos povos pelo conhecimento do direito estrangeiro remonta à antiguidade. Assinala-o Mario Sarfatti, (Le Droit Comparé dans son essence et dans son aplication), apresentando como exemplo a colheita de materiais constante da Lex Dei ou Collatio legum Romanarum et Mosaicarum, que surgiu no ano 400 da Era Cristã.

Fôrça é reconhecer, todavia, com Giorgio del Vecchio, (Sull'Idea di una Scienza del Diritto Universale Comparato, 2. ${ }^{a}$ edição, p. 24), que foi Anselm Feuerbach (1775-1833), quem lançou de fato os fundamentos da ciência do Direito Comparado.

Feuerbach era um criminalista. Publicou, aos vinte e cinco anos de idade, o Ensaio de uma Ciência Criminal do Corão. E o seu interêsse esteve sempre voltado para o estudo do direito em outros povos. A sua obra, porém, inédita na maior parte por dilatados anos, só recentemente foi revelada, após os trabalhos - de Gustav Radbruch, professor da Universidade de Heidelberg, que lhe traçou a biografia. 
O legado científico de Feuerbach abrange estudos, alguns inacabados, sôbre as normas vigentes na Sibéria, na Mandchúria, na Mongólia, na China, na América. Os dados de que dispunha eram contudo bem modestos. Compunham-se, em sua maior parte, de narrativas dos viajantes, sem formação jurídica, os quais preferiam descrever "os costumes, a alimentação, as bebidas e aquilo que chama a atenção do vulgo, a falar de assuntos concernentes à organização jurídica, os quais, embora mais ocultos, solucionam, entretanto, mais que êsses aspectos exteriores, o enigma da humanidade", (apud Gustav Radbruch, Anselm Feuerbach, précurseur du Droit Comparé).

Proclamava Montesquieu, em 1748, no seu Esprit des lois, Livro I, capítulo 1. ${ }^{\circ}$, que "La loi en général est la' raison humaine, en tant qu'elle gouverne tous les peuples de la terre, et les lois politiques et civiles de chaque nation ne doivent être que les cas particuliers où s'applique cette raison humaine. Elles doivent être tellement propres au peuple pour Iequel elles ont été faites que c'est un très grand hasard si celles d'une nation peuvent convenir à une auutre".

Fundada em tal concepção nasceu a escola histórica, para a qual o direito decorria do "Volksgeist", do espírito do povo, isto é, das particularidades da vida de cada nação. Sem negar, contudo, essa verdade: "Todo povo traz no seu coração, com o seu sentimento humano e sua particularidade étnica, o gérmen de sua legislação, Feurbach acrescentava: "A legislação, como parte essencial da cultura do espírito, propaga-se de um povo a outro".

E' o que assinalam Arminjon, Nolde e Wolff, (Traité de Droit Comparé, I, 12), ao afirmarem existir normas puramente arbitrárias, que poderiam, sem inconveniente, ou injustiça, ser substituídas por outras, como as concernentes $\dot{a}$ idade em que a pessoa atinge à maioridade, ou as referentes aos prazos da prescrição. "Quando um legislador elabora uma lei, êle não se inspira apenas na justiça abstrata, mas, sobretudo na utilidade, êle considera aquilo que pode razoàvelmente fazer, êle toma, ou deve tomar em consideração os costumes, os hábitos, as tradições e mesmo 
os prejuízos da população. Demais, a mesma finalidade pode ser obtida por diversos meios. Como em tôdas as ciências aplicadas, a atuação do direito pode operar-se por processos muito diversos, seguindo métodos práticos que parecem diferir completamente e que todavia atingem o mesmo escôpo através caminhos mais ou menos curtos e mais ou menos diretos e apropriados".

A semelhança, ou identidade das leis que governam os povos diversos decorre de vários fatôres. Nasce da conquista, da colonização, da imitação. Simples influência de leis estrangeiras, em dados casos, adoção integral de textos legais alienigenas em outros.

O Código Comercial Francês, de 1807, vigorou na Penìnsula Itálica até 1814, no Cantão de Genebra até 1883, na Holanda e na Bélgica, por largo tempo. Aproveitou-se, no Haiti, o seu conteúdo, em 1826, dando-se embora outra disposição à matéria e diversa numeração aos artigos. Adotou a Turquia, há cêrca de trinta anos, o Código Civil e o Código das Obrigações da Suissa; seu Código de Processo é o do Cantão de Neuchâtel...

Tivemos no Brasil, no concernente à matéria, um eloquente exemplo. Havendo a lei de 20 de outubro de 1823 mandado vigorar no Império, "em quanto se não organisar hum novo Codigo, ou não fôrem especialmente alteradas", as Ordenações, Leis, Regimentos, Alvarás, Decretos e Resoluções promulgados pelos reis de Portugal e pelos quais o país se governou até 25 de abril de 1821 , "em que S.M. Fidelissima, actual Rey de Portugal e Algarves se ausentou desta Côrte", - revalidou a vigência entre nós da lei de 18 de agôsto de 1769. E havendo tal lei recomendado que se recorresse, como legislação subsidiária, às "Leis das Nações Christãs, illuminadas e polidas, que com ellas éstão resplandecendo em boa, depurada e sã Jurisprudência", vimos por vêzes aplicadas, até 1850 , por juízes e tribunais, as normas do Código de Comércio Francês.

Foi a França que, reconhecendo a importância do estudo do Direito Comparado, inaugurou no Colégio de França, em 1839, a primeira cadeira dessa disciplina. E, 
em 1869, fundava-se em Paris a primeira Sociedade de Direito Comparado.

A esta, outras notáveis instituições se juntaram, recolhendo documentação, ou favorecendo os estudos do Direito. Comparado. Assim na Alemanha a Associação Internacional de Direito e Economia Política Comparados, (Internationale Vereinigung für vergleichende Rechtswissenschaft und Volkswirtschaftslehre), fundada em Berlim em 1894, pelo juiz Felix Meyer; na Itália, o Instituto de Direito Comercial Comparado, da Universidade Bocconi, de Milão e o Instituto de Estudos Legislativos, de Roma; na Bélgica, o Instituto Belga de Direito Comparado; na França, o Instituto de Direito Comparado, de Lyon; no Brasil, a Sociedade de Direito Comparado, do Rio de Janeiro.

Cumpre assinalar, outrossim, o esfôrço desenvolvido pela unesco, no sentido de incrementar os estudos jurídicos no campo do Direito Comparado assim como, dentro de sua esfera especial, a atividade desenvolvida pela Organização Internacional do Trabalho, sita em Genebra.

Cresce dia a dia a atenção que merecem os esfudos do Direito Comparado, quando vemos se intensificarem as relações entre os países, mais próximos ou mais remotos, graças às facilidades de comunicação, propiciadas pelo progresso. O conhecimento do direito de um e outro Estađo leva-nos a uma compreensão mais perfeita de sua índole e de sua civilização. E' assim um precioso contributo para a paz entre todos os povos.

E' o que muito bem exprimiu Tullio Ascarelli, (Saggi Giuridici, p. 5), ao escrever que "o direito comparado representa o instrumento para a formação de uma "linguagem" jurídica internacional. Reforçar e desenvolver no direito uma linguagem ideal, internacionalmente uniforme, significa, ao mesmo tempo, contribuir para uma compreensão sempre maior e, dessa maneira, a uma cooperação internacional sempre crescente"

Eis como René David, (Traité Élémentaire de Droit Civil Comparé, p. 33), proclama que, "em todos os domínios 
o método comparativo pode, em numerosas hipóteses, ser empregado com resultado. 0 jurista que não está apto a empregá-lo e que não se dá conta da utilidade dêste método, está privado de um meio, frequentemente essencial, com a ajuda do qual poderia melhor desempenhar sua tarefa; êle não conhece senão imperfeitamente seu mister, não sendo para êle uma excusa dizer que não é comparatista: todo jurista que visa estar à altura de sua tarefa deve ser um comparatista".

o Direito Comparado como disciplina auxiliar. - As noções expostas até agora valem como um ligeiro escorço, através da História, para demonstrar o interêsse sempre manifestado pelo estudo do Direito Comparado.

Não obstante instituída no Colégio de França, em 1839, a cadeira de História Geral e Filosofia da Legislação Comparada e haver a reforma Benjamin Constant criado no Brasil, em 1891, nas Faculdades de Direito, a cadeira de Legislação Comparada, entende Naojiro Sugiyama, (Essai d'une concéption synthétique du Droit Comparé), que o nascimento efetivo dêsse direito apenas ocorreu após o Congresso Internacional de Direito Comparado, realizado em Paris em 1900.

Confiara-se nesse ano a Edouard Lambert a cátedra de História Geral do Direito, na Faculdade de Direito de Lyon. E apresentava êle no Congresso de Paris o trabalho intitulado - Conception générale, définition, méthode et histoire du Droii Comparé..

Foi êsse eminente jurista na Europa, a partir dêsse instante, um dos mais devotados apóstolos, no culto dessa disciplina jurídica. Fundou, a princípio, o Seminário Oriental de Estudos Jurídicos e Sociais, que se transformou, após a guerra de 1914-1918, no Instituto de Direito Comparado, da Faculdade de Direito da Universidade de Lyon. $\mathrm{E}$ a sua Faculdade, no momento da aposentadoria do eminente mestre, prestou-lhe a mais significativa das homenagens, reunindo, em três alentados volumes, os estudos elaborados pelos mais notáveis especialistas do mundo, sôbre 
os problemas do Direito Comparado. (Vêde Introduction à l'étude du Droit Comparé - Recueil d'Etudes en l'honneur d'Édouard Lambert, Librairie de la Société Anonyme du Recueil Sirey, 1938).

Toma o estudo do Direito Comparado um largo desenvolvimento nos vários continentes. Separam-se os juristas em sua conceituação - como mera disciplina auxiliar, como simples método, como ciência autônoma.

Relativamente ao objetivo do Direito Comparado, reune Sugiyama as diversas escolas, ou tendências, em três categorias: a) as que visam estabelecer a essência fundamental do direito, ou seja, as leis, ou rítmos de sua evolução; b) as que têm por escôpo investigar o direito positivo; c) as que porfiam em realizar o progresso do direito positivo.

O professor Lino de Moraes Leme reune as tendências assim expostas em quatro grupos: a científica, a legislativa, a subsidiária do direito nacional e do direito internacional privado, a teórica e prática. A nós nos parece que, guardando as bases da classificação de Sugiyama, poder-se-ia dizer que tais escolas, ou tendências, se orientam por estas diretrizes: a) científica; b) legislativa; c) evolutiva.

Em seu interessante estudo, o eminente professor da Faculdade de Direito da Universidade Imperial de Tóquio desce a uma análise mais profunda, subdividindo essas várias escolas em diferentes matizes.

Da sintese admirável de Sugiyama bem se apercebe o estudioso do direito da complexidade da matéria. Nem sempre é facil classificar êste ou aquêle jurista em uma e outra categoria. Baste assinalar que o próprio mestre japonês coloca Lévy-Ullmann, ao mesmo tempo, na escola da jurisprudência comparativa dos diversos grupos do direito, da primeira categoria e na escola da ciência universal relativa do direito comparado, da terceira.

Surge, todavia, a primeira e mais importante divergência entre os autores, quando se trata de conceituar o Direito Comparado como disciplina auxiliar, como simples método, como ciência autônoma. 
No estudo dos vários ramos do direito invocamos, a cada passo, para ilustração do curso, as leis, a jurisprudência, a doutrina de outros povos. No conflito de leis que se defrontam, no campo do Direito Internacional Privado, aplicam os tribunais contìnuamente a legisląção estrangeira. Busca o legislador muitas vêzes inspiração em normas alienígenas, para a formulação de novos estatutos jurídicos. O Direito Comparado surge, assim, como disciplina auxiliar.

Mas, aí, seu campo de ação fica limitado pelo próprio problema que se investiga. Não há dúvida que a simples comparação de dois sistemas jurídicos seja do âmbito do Direito Comparado, assinalam Arminjon, Nolde e Wolff, (op. cit., I, 23). "Kaden anota: " $\mathrm{A}$ ' vista da noção do Direito Comparado pouco importa que o número dos sistemas jurídicos postos em confronto seja grande ou pequeno".

E continuam os mesmos autores: "Não é menos certo que o Direito Comparado, limitado ao estudo de um número restrito de sistemas jurídicos, não seria mais que uma disciplina auxiliar. Servirá para compreender melhor os sistemas que fazem objeto da comparação, mas, não poderá senão muito parcialmente, caracterizar a vida jurídica da humanidade tomada em seu conjunto".

o Direito Comparado como simples método. - Notáveis escritores sustentam que o Direito Comparado nada mais é senão o método comparativo posto ao serviço do direito. Dessa opinião participam Kaden, De Francisci, René David, Lino de Moraes Leme.

Kaden assim expressa o seu ponto de vista: “A noção do Direito Comparado. . não compreende outra coisa além de um método de pesquisas jurídicas. O Direito Comparado em nosso entendimento não pode, como tal, pretender ser definido como uma ciência; seu objetivo não passa da comparação das regras dos diferentes sistemas jürídicos; ela não mostra diretamente senão a similitude ou a diversidade das diferentes soluções que um só e mesmo problema recebeu na maioria dos sistemas jurídicos. Isso 
indica, de um lado, que o Direito Comparado depende da matéria que faz objeto de seu estudo e, de outro lado, que êle não colima extrair um sistema de concepções de valor objetivo das regras jurídicas que êle compara e de as construir", (apud Arminjon, Nolde e Wolff, op. cit., I, ibidem). E' o mesmo conceito de De Francisci, para quem "um método comparativo existe. mas, uma ciência particular de Direito Comparado não existe, nem poderia existir"...

Êsse é também o pensamento de René David, (op. cit., p. 3), que assim se pronuncia: "A expressão Direito Comparado, porque ela evoca uma analogia com diferentes ramos do direito positivo, que constituem tantos ramos da ciência jurídica, é uma expressão infeliz, que teria vañido e que seria melhor evitar. Muitas discussões inúteis teriam sido evitadas se, em vez de Direito Comparado, se tivesse falado com certos autores, seja de comparação de direitos, seja de método comparativo. O Direito Comparado não é outra coisa com efeito que a comparação dos direitos, é o método comparativo aplicado no domínio das ciências jurídicas".

Nessa corrente se inscreve Lino de Moraes Leme que desta forma expressa o seu ponto de vista: "A função técnica do Direito Comparado é a de procurar a constância e a variedade nas regras de direito e nos institutos jurídicos. Com êsse escôpo o Direito Comparado constitui o processo fundamental da ciência do direito, que é a de procurar a constância e a variedade nas regras do direito e nos institutos jurídicos, concorrendo para a descoberta dos princípios reguladores da evolução jurídica", (Revista da Faculdade de Direito de Sâo Paulo, 47/181).

$O$ Direito Comparado como ciência autônoma. - Não obstante o pronunciamento de juristas tão eminentes, entendemos que o Direito Comparado erige-se em disciplina autônoma, constituindo o ramo das ciências jurídicas que, da investigação, análise e crítica das instituições e sistemas jurídicos dos vários povos, procura extrair os princípios. fundamentais comuns, que informam tais legislações e terão assim possibilidade de aplicação universal. É tal 
sentido que Lévy Ullmann considera o Direito Comparado o ramo da ciência jurídica que tem por objeto a aproximação sistemática das instituições dos países civilizados.

Impossível nos será, sem dúvida, estudar pormenorizadamente cada uma das escolas e tendências que surgiram no campo do Direito Comparado. Limitar-nos-emos, pois, a aludir, embora com brevidade, às doutrinas sustentadas por dois grandes mestres do direito francês: Raymond Saleilles e Édouard Lambert.

Para Saleilles, o Direito Comparado, como ciência autônoma, tem por objeto: primo, o estudo das diversas legislações, pelo seu aspecto social; secundo, dadas as semelhanças orgânicas de certos grupos, a aproximação das construções jurídicas e práticas reveladas pelo estudo isolado das instituições; tertio, a apresentação de um, ou vários tipos jurídicos resultantes desta crítica comparativa e destinados à orientação progressiva das legislações particulares, sob reserva das formas tradicionais e das diversidades históricas que as distinguem" (Conf. Conception et objet de la science du droit comparé, apud Arminjon, Nolde et Wolff, op. cit., I, 37).

Reconhece Saleilles a impossibilidade de se chegar a um tipo único de legislação, para o qual deve tender o progresso da humanidade. Visando a formação de um direito comum aos vários países tem como evidente a impossibilidade de se atingir a um direito único para todos os povos. "Onde quer que exista uma unidade forçađa, há imobilização e entrave no progresso: a diversidade é produto da vida e a concorrência é a norma da vida", (ibidem).

As idéias dêsse autor defluem de seu conceito do direito natural. Para êle, o direito natural existe, os legisladores e magistrados devem considerar seus preceitos, mas seu conteúdo é variável: é um ideal relativo, correspondente ao estado social e às aspirações de uma determinada sociedade.

O pensamento de Lambert, contido na exposição por êle apresentada no Congresso Internacional de Direito Com- 
parado de 1900, foi depois desenvolvido em seu livro Études de Droit commun législatif. La fonction du Droit Civil Comparé, publicado em 1903.

Entende Lambert que é mister distinguir no Direito Comparado duas ciências distintas: a História Comparativa e a Legislação Comparada. " $\mathrm{E}$ ' necessário opôr uma à outra", escreve, "duas ciências distintas, que se confundem sob a expressão Direito Comparado. A primeira é a ciência dos fenômenos jurídicos, ela tem por objeto o conhecimento das leis da vida juridica, compreende tôdas as legislações, mortas ou vivas, as que se adaptam aos tipos inferiores de civilização, como as que se aplicam aos tipos superiores. A segunda, elemento do direito positivo, deve, sob pena de improdutividade, seriar sua ação e limitá-la a um certo número de direitos vivos e ligados por um laço de parentesco. A matéria prima sôbre a qual ela trabalha varia segundo o tempo e os lugares" Chega Lambert a preferir à denominação Legislação Comparada uma outra: Direito Internacional Privado ou Civil.

Reduzindo o Direito Comparado, sob êste aspecto, à Legislação Comparada, chega o eminente professor de Lyon a proclamar ser esta uma simples arte. "Ce n'est plus une science, c'est un art".

Examinando êste ponto de vista, escreve Alexandre Otetelisanu, professor da Faculdade de Direito da Universidade de Bucarest: "Acreditamos que a opinião na qual se considera o Direito Comparado como uma arte e não como uma ciência explica-se sòmente pela idéia de considerar o Direito Comparado sob o ângulo das aplicações práticas, e não também sob o ângulo da elaboração das verdades jurídicas que o Direito Comparado nos dá a possibilidade de estabelecer". E, após outras considerações referentes à matéria, acentua: "Tôda ciência e tôda arte possuem sua técnica. O Direito Comparado também possui a sua, que nós chamamos "política jurídica", mas, alěm desta técnica, o Direito Comparado permanece sempre uma ciência. E' uma ciência pela qual se descobre o aspecto unitário de uma instituição jurídica ou as tendências co- 
muns desta instituição, estudando-a nas diferentes legislações pertencentes a povos de uma civilização idêntica ou similar. Uma vez estabelecidas estas verdades, a técnica, a arte, ou a política jurídica - o nome pouco importa intervém para fazer as aplicações práticas". (Conceptions d'Edouard Lambert sur le Droit Comparé, in Recueil d'Études cit., I, 41).

Chamar-se Direito Internacional Privado ou Civil, de outro lado, à Legislação Comparada, seria estabelecer $a$ priori a unificação do Direito Privado e confundir também matérias de conteúdo tão diverso, como o Direito Internacional Privado e o Direito Comparado.

Reconhecendo, embora, haver Édourd Lambert realizado uma obra imensa, em sua cátedra de Lyon, na fixação dos princípios fundamentais que formam o arcabouço do Direito Comparado, dêle divergimos quando sustenta haver nesse direito duas disciplinas distintas - a História Comparativa e a Legislação Comparada. Os elementos dessas duas disciplinas se fundem para formar o ramo da ciência jurídica que ora estamos a estudar. Não é possível, em verdade, compreender o Direito Comparado sem investigar, no passado, as instituições existentes e seguir-lhes a evolução através dos tempos.

Ficariamos exclusivamente no campo da História do Direito se nos detivéssemos, nessa investigação, sem buscar nos sistemas jurídicos vigentes os elementos de estudo imprescindíveis para descobrir os princípios comuns que os informam, demonstrando uma tendência universal de atitudes entre os povos que atingiram igual estádio de civilização. O Direito Comparado não é, assim, na expressão de Arminjon, Nolde et Wolff (op. cit., I, 30), "um simples meio de compreender melhor as instituições jurídicas e as leis nacionais e estrangeiras. Em virtude de seu caráter normativo, é uma disciplina autônoma, da mesma forma que a história e a filosofia".

Tendo em conta quanto expuzemos até agora, poderemos dizer que o Direito Comparado é o ramo da ciência juridica que tem por objeto, através da investigação his- 
tórica e do estudo das várias legislações, estabelecer os princípios comuns que devem nortear a vida jurídica dos povos, inspirando, por êsses conhecimentos, o desenvolvimento do direito em tôdos êles".

Suas divisões. - E' clássica a divisão do direito vinda dos romanos, segundo a norma de Ulpiano, (Digesto, Livro I, De Just. et jure, Tit. 1.0: "Hujus studii duoe sunt positiones, publicum et privatum. Publicum jus est, quod ad statum rei romanae spectat. Privatum, quod ad singulorum utilitatem" Por êsse conceito, inscrevem-se geralmente no campo do Direito Público o Direito Constitucional, o Direito Administrativo, o Direito Penal, o Direito Judiciário Civil, o Direito Judiciário Penal; o Direito Privado compreende o Direito Civil e o Direito Comercial.

Com as últimas conquistas da ciência, vencendo os limites do espaço aéreo, em relação ao qual se haviam estabelecido normas jurídicas geralmente aceitas pelos povos, outras disciplinas jurídicas vão surgindo, as quais fogem do díptico estabelecido desde o tempo dos romanos.

Os foguetes, que ultrapassaram a atmosfera terrestre, os satélites artificiais, que se movem no espaço, na órbita da Terra, ou na órbita do Sol, impuseram a formação de novas disciplinas jurídicas, que não podem ser compreendidas na área do Direito Privado, ou do Direito Público, mas, requerem para si uma categoria especial. Daí havermos imaginado um novo tronco, em que se articulariam os novos ramos: o Direito Espacial, compreendendo o $D \vec{i}$ reito Astronáutico e o Direito Interplanetário.

Por certo que não temos algo a comparar no campo dêsses direitos em formação. Mas, o Direito Comparado, no âmbito de suas investigações, abrange a variedade dos direitos vigentes nos vários países. Haverá, de tal arte, um Direito Constitucional Comparado, um Direito Administrativo Comparado, um Direito Penal Comparado, um Direito Processual Comparado, entre as disciplinas jurídicas filiadas ao Direito Público, da mesma sorte que existe um Direito Civil Comparado, um Direito Comercial Comparado, entre as que compóem o Direito Privado. 